\title{
Sustainable Tourism Development of Landscape Heritage in a Rural Community: A Case Study of Azheke Village at China Hani Rice Terraces
}

\author{
Lin Zhang ${ }^{\text {a* }}$ and William Stewart ${ }^{\mathrm{b}}$ \\ a College of Architecture and Urban Planning, Tongji University, Shanghai, China \\ $b$ College of Applied Health Sciences, University of Illinois, Urbana-Champaign, USA \\ *Corresponding author: tongjizhanglin@163.com
}

\begin{abstract}
According to the World Heritage Convention, rural landscapes are evolving cultural landscapes and their heritage and management is a major international concern. The proposal of 'UNESCO World Heritage Sustainable Tourism (WH+ST)' has enlightened different arguments about protection and utilisation of the value of rural landscape heritage. The Outstanding Universal Value (OUV) of rural landscapes results from the interaction of nature and humankind. Local community residents are critical for the sustainable tourism development of rural landscape heritage. Landscapes would lose their authenticity and integrity without participation of community residents. At the same time tourism is promoting the economic development of communities, tourism will affect its natural environment and social culture in varying extents. Because of such impacts, rural landscapes are subject to the risk of becoming overly commercialised. In this sense, the discussion will focus on how to achieve balance among the various forces stemming from protection of the OUV of rural heritage, economic development and sustainable community-based tourism. This paper is based on field research at the World Heritage Hani Rice Terraces at Azheke Village (Yunnan Province, China). At this site, the agricultural landscape, architectural design, rural culture, and social traditions have confronted challenges because of the rapid development of the tourism industry soon after designation as a World Heritage Site in 2013. The planning was carried out in respect of three key problems: (1) How to motivate community residents' sense of recognition and honour of the heritage value? (2) How to create the manner and approach for the community residents to participate in rural sustainable tourism? and (3) How to improve the social residents' interests in the course of developing rural heritage tourism? Specific planning measures and suggestions have also been proposed in hopes that community residents take the initiative to protect, utilise and undertake the OUV of the Hani Rice Terraces.
\end{abstract}

KEYWORDS rural landscape, world heritage, sustainable tourism, community participation

Received March 17, 2017; accepted December 11, 2017.

\section{Introduction}

The rural landscape, as the 'combined works of nature and humankind' (UNESCO 2015), originated from the people's production and utilisation of natural resources. When a rural landscape has existed for decades in a sustainable and mutually beneficial set of relationships between nature, society and economic production, a cultural landscape is produced reflecting a unique heritage. If the landscape is considered one that has 'organically evolved landscape' and carries Outstanding Universal Value (OUV), it will be recognised by UNESCO as a World Heritage Site.
Throughout the world, farmers, herdsmen and fishermen utilise local natural resources in particular ways that integrate conditions of the land, its hydrologic system and climate conditions across several generations to create, develop and maintain some specialised agricultural production technology that forms a unique ecosystem, landscape environment and folk culture. This landscape diversity is, for the most part, a result of the variety of land-uses that have overlaid, refined or replaced each other throughout history (Plieninger et al. 2006).

The world has a variety of significant rural landscapes with prominent diversity, regionalism and on-going 
human activity that comprise designated World Heritage sites. These rural landscapes including Cinque Terre (Italy), the Rice Terraces of the Philippine Cordilleras (Philippine), the Cultural Subak System as a Manifestation of the Tri Hita Karana Philosophy (Bali Province, Indonesia) and Historic Villages of Shirakawa-go and Gokayama (Japan) have been ranked in the World Heritage List in succession; and Honghe Hani Rice Terraces (China covers 16,603 ha in Southern Yunnan) was ranked on the World Heritage List at the $37^{\text {th }}$ Session of the World Heritage Committee that convened in 2013.

With the promotion and global interest in heritage, the sites have evolved to serve dual priorities: to preserve heritage while educating and entertaining tourists (Donohoe 2012). Heritage sites have become important tourism destinations (Ryan and Silvanto 2010); however, tourism development brings about both opportunities and challenges to the World Heritage. Nations have recognised that the heritage is an important tourism asset, and by extension, it is an important source of revenue for site management (Timothy 2003). Consequent social problems that result from tourism development of the heritage sites need to be addressed in order to protect them. The World Heritage Committee recently supported the need to develop sustainable tourism programs for cultural landscapes linked to UNESCO designation of World Heritage (2010, 34COM5F.1 of the $34^{\text {th }}$ Session of the World Heritage Committee in Brazil which was formally approved in the $36^{\text {th }}$ Session of the World Heritage Committee, 2012, 36COM5E). Thus the 'World Heritage and Sustainable Tourism Programme (WH+ST)' was included in the strategic action plan of the World Heritage Convention (WHC-11/18.GA/11) and expected to be implemented from 2012 to 2022 under the coordination of the World Heritage Centre. The World Heritage and tourism stakeholders shall share responsibility for the conservation of our common cultural and natural heritage of OUV and for the sustainable development through appropriate tourism management (UNESCO 2013).

The problems of rural landscape heritage were especially problematic. As the rural landscape heritage sites are usually located in remote places with rare connections with the outside world, the traditional way of tillage and farming practices, the living behaviours and lifestyle patterns, and the social and cultural traditions have been still maintained. While tourism development has changed the interaction between people and nature, in turn, the relationships between lifestyle patterns, farming practices, and new development to service as growing tourism industry have all withstood significant impacts.
The Azheke Village of Hani Rice Terraces characterises some typical problems that could be transferable to other rural World Heritage Sites. The Hani reside in a traditional village, and over decades their cultural landscape could be characterised as a four-element system of 'forest-water system-village-terrace.' Their traditional way of tillage and living patterns have not changed for centuries in part due to their remote geographic locale and lack of modern transportation infrastructure to connect with the outside world. Nevertheless, upon designation as a World Heritage site, tourists have been drawn to it in unprecedented numbers. As a result, the landscape environment was greatly damaged, the conflicts and problems among the tourists, the villagers and the local government increased in intensity and breadth. The OUV of the heritage site was jeopardised while the development of local community was also affected as well. The local government was entrusted with planning and implementing sustainable tourism development. World Heritage Sites will inevitably draw tourists and require careful planning to sustain both the tourism industry and the protection of the qualities that comprise its uniqueness.

The planning team was aware that the onus of responsibility for implementation shall fall on the local residents. It was up to the community to achieve sustainable development of its heritage tourism. However the planning team worked with the community to protect, utilise and undertake the OUV of World Heritage of Hani Rice Terraces. In particular, the planning team respected the life and culture of local community residents and directed efforts to improve the community's recognition of heritage value and sense of belonging. The planning team also wanted to create opportunities for the community residents to participate in heritage tourism and improve their living level and actual interests while maintaining its authenticity, integrity and regionalism.

\section{Theoretical Framework}

\section{Rural Landscape}

In 1962, the UNESCO Recommendation concerning the safeguarding of the beauty and character of landscapes and sites defined two concepts that would guide World Heritage List (WHL) nominations: preservation of the beauty and character of the landscape, and the protection of natural and rural landscapes (UNESCO 1962). Rural landscapes refer to the cultural landscapes arising from consecutive land reorganisations (Añón Feliú 2003). Rural landscapes reflect changes and evolution of their human 
society that inhabits them while also reflecting the adaptation of technology at different historic times (Lennon and Han 2012). Land utilisation in traditional patterns continues to survive and support the biodiversity of various regions in the world (Taylor and Lennon 2011). The interaction between mankind and their natural environment is thus considered as the unique universal value. Each of these sites is recognised as the cultural heritage for its distinctive agricultural system (Gullino and Larcher 2013). Rural landscapes include three aspects of the rural ecology, production and living, which are closely related to social economy, and folk customs and spiritual aesthetics (Liu and Chen 2013). The agricultural landscape, the rural settlement landscape and the cultural landscape have thus constituted the key elements of rural landscapes as possessing authenticity, integrity and sustainability.

- Authenticity: The rural landscapes rely on the rural dwellings that were made from villagers' handiwork in a traditional way of working, adhering to folk customs and local specialties in skills (Peng 1992). These specific forms of rural life and working have thus constituted the identifiers and environment perceptions of the characteristics of rural landscapes.

- Integrity: Rural landscapes rely on both cultural and natural features that are key to the site's identity (Gullino and Larcher 2013), including the ecological pattern, the traditional settlement landscape and the basis of its rural culture. The most critical are the rural natural geographic characteristics with their native social and cultural contexts. The relationship between culture and nature is best to characterise the integrity of a rural landscape rather than either nature or culture alone (Gullino and Larcher 2013).

- Sustainability: These sites will be an 'organically evolved sustainable landscape.' The landscape is vital and maintains its active social functions. In the interaction between human and nature, the rural landscape and the rural life style have been protected, Yet they are still functioning and under development. These traditions which continue up to now, in spite of changes, are still playing important economic and cultural roles in modern society.

\section{Sustainable World Heritage Tourism}

World Heritage is a major resource for global tourism. Almost all individual World Heritage properties are significant tourism destinations (UNESCO 2010). A number of studies identify heritage as one of the most significant and fastest growing components of tourism (Poria et al. 2003,
Timothy 2003). The World Heritage brand exerts more impact upon tourism to lesser-known properties than to iconic properties and attract tourists. The local traditions, including arts and crafts, lifestyle, cuisine, and dances, as well as municipal heritage sites such as buildings, parks, and museums, serve as key attractions in the heritage tourism industry (Lee et al. 2016). However, tourism, if managed well, can benefit the World Heritage properties realise economic benefits and assist in understanding and protecting the OUV of the World Heritage. If not, it will threaten the World Heritage properties, among which the most significant threat refers to 'the commercialisation of heritage over conservation values.' (Noha 2003). As indicated by some researches, World Heritage sites are increasingly adopted as a tool for national tourism marketing campaigns (Drost 1996). Heritage tourism is widely deemed as a tool for community economic development and often actively promoted by local governments and private businesses (Chhabra et al. 2003). For example, the Chinese local governments with administrative jurisdictions over the World Heritage sites have to satisfy visitors in order to have a good word-of-mouth effect and attract more visitors because these sites are regarded as new sources of income, but increasing to a vast visitors would constitute a major threat to the protection of such sites (Shen et al. 2009). The conflict between protection and heritage tourism has become a challenge.

The sustainability of tourism development at heritage sites has been an increasing concern. Discussions have focused on sustainability and how sites can develop practices, principles and management strategies which may contribute to the long-term viability of the heritage attractions and destinations (Weiler and Kim 2011). Thus the World Heritage and Sustainable Tourism Programme (WH+ST) was officially passed in the $36^{\text {th }}$ Session of the World Heritage Committee in 2012 (36COM5E), which may facilitate the management and development of sustainable tourism at World Heritage properties by means of cultivating increased awareness, capacity and balanced participation of all stakeholders. In addition to the combination of sustainable tourism and sustainable agriculture, a responsible way of economic development would be conducive to improve the community's welfare (Knowd 2006); however, the relationship between protection and improvement is substantially tense and complex. Sustainable tourism at heritage sites usually encounters pressure and challenges in the course of implementation.

Different from the tourism in general, the heritage tourism expects to highlight the protection, the 
representation, the interpretation and the utilisation of the universal value of the heritage sites. All tourism projects and facilities shall be developed in adherence to its OUV; therefore, key attention shall be paid to the relationship between tourists and the spaces visited in terms of identifying the value sought and gained from visiting heritage attractions (Poria et al., 2006a, 2006b).

Under this circumstance, heritage tourism shall not pursue the extensive development characterised by the objective of tourist increase but deeply understand and represent the heritage's OUV while achieving the tourist's affective commitment so as to increase the opportunity for preserving the heritage site in the future. Sustainable tourism promotes stakeholders' action, enables them to understand, cherish and protect the OUV of rural heritage sites, offers high-quality tourism products and services with affection, education and protection against development of the rural landscape, culture and the life style.

\section{Community-based Sustainable Tourism of Rural Landscapes}

Communities have been universally concerned for the protection and development of heritage sites. The management philosophy of heritage sites in China has evolved from the 'laissez faire manner' and 'residents relocation approach' to the recent 'common evolution of mankind and nature' and the 'emphasis on the community value and the sustainable development' (Wang 2014). As definitely pointed out in the $21^{\text {st }}$ Century Agenda, 'the public shall participate in the environmental governance and the decision-making', 'the local people's own features and cultural interests shall be recognised and fully utilised to enable them involved in the sustainable development practices effectively' (United Nations 1992). The World Heritage Committee upgraded the World Heritage strategy from ' $4 C$ ' to ' $5 C$ ' in 2007 , that is, the concept of 'community' was added to 'credibility', 'conservation', 'capacitybuilding' and 'communication' so as to emphasise the significance of local communities to the World Heritage and its sustainable development (Tong 2012). In 2012, the World Heritage Committee even confirmed the theme as 'World Heritages and Sustainable Development: the Role of Local Communities', 'the relocation of all communities from heritage sites for reducing the pressure of human activities on heritage protection failed to observe heritage protection principles of authenticity and integrity' (Han 2012). The local communities shall be deemed as integral parts with priority concerns in the heritage planning; therefore, they shall completely participate in all processes of planning, decision-making, implementation and control from the very beginning (Tazim and Getz 1995; Loulanski and Loulanski 2011).

For tourism development at heritage sites, community involvement shall be a central tenet of the concept of sustainable tourism (Bramwell and Sharman 1999); and it is vital to understand the local residents' attitudes towards tourism development for the success and sustainability of tourism (Dogan et al. 2010). Tourism development has not only changed the physical environment of the destination but affected the society, the culture, and the residents' living quality (Kang et al. 2008). When tourism development is intensified beyond a community's capacity, the social life of a community would undergo tremendous changes (Richard et al. 1995). Taking the British heritage of Avebury as an example, as the local residents lacked connection with the World Heritage, the local people had less sense of being masters and showed great dissatisfaction with the excessive tourists. They believed it would not be their choice to be listed as the heritage site; on the contrary, it has exerted enormous effects on their life (UNESCO 2015). As also verified by the Baghdad case, unless the city authorities were able to maintain the balance between the needs of the indigenous population and the tourists, there would be indeed possibilities that a new legitimation crisis would emerge (Cooper and Morpeth 1998); therefore, 'the sustainable integration of cultural heritage and tourism shall cover local involvement, balance of authenticity and interpretation and shift towards sustainability-centred tourism management and practice' (Loulanski 2011). At the rural heritage sites, their tourism development cannot be carried out without participation of the local residents, as a part of the heritage sites; in this sense, the rural landscapes shall be also characterised by the organic integration of mankind and nature. If the participation of local community residents is lost for rural tourism, the rural landscape would lose its authenticity and integrity and the local identity would slowly change from an agricultural place to a place for rural recreation and myths (Hopkins 1998), but this commercialised cultural heritage would lose its content and finally become a 'staged authenticity' (MacCannell 1973).

\section{Research Objective}

As far as we are concerned, tourism may uphold some aspirations as a partial solution to the economic problems of rural communities and the connections between community history groups and tourism are valuable; but the development of heritage tourism brings about challenges 
to the integrity of the community and its heritage (Gilbert 2006). Although we have been always emphasising the OUV of rural heritage sites, if the local residents cannot feel the significance of such value or get experience or income from such value, they will feel marginalised, which is a very critical issue. Therefore, the aim of the project is to discuss how to balance the relationship among the OUV, the community development and the sustainable tourism of rural heritage sites so as to achieve mutual promotion, integrated development by means of cultural self-consciousness, functional regeneration and in vivo protection.

- How to motivate the sense of identity and honour among local community residents to enable them to take initiatives in the protection, representation and management of rural landscape heritage in the course of tourism development, and enable the heritage tourism to function as the bridge connecting the community residents and the heritage value?

- How to create the method and approach for the community residents to be engaged in the sustainable rural tourism, enable the tourism industry to instruct behaviours of the local community residents in an active and positive manner, enable them to be engaged in the tourism activities in which they are interested in and able to participate, and thus protect the authenticity, integrity and diversity of rural landscape value in daily life?

- How to improve the interests of the community residents in the course of developing the rural heritage tourism? The indigenous peoples shall be maintained by life improvement to gain their support. Finally, as the 'connection' of the value carrier in the course of continuation, these indigenous peoples thus further undertake the 'context' of heritage value and achieve the unity of form and spirit.

\section{Background of the Study Site}

In Xinjie Town, Yuanyang County, Honghe Prefecture, Yunnan Province, China, Azheke Village is located at the core area of the Honghe Hani Rice Terraces World Heritage Site, halfway up Ailao Mountain with an altitude of $1,880 \mathrm{~m}$ and covering an area of $1.43 \mathrm{~km}^{2}$. As one of the five representative villages of the World Heritage sites, its location has completely represented the OUV of Hani Rice Terrace; therefore, it is included in the nomination element of the heritage site (Figure 1).

Azheke, in Hani language, refers to exuberant forest where a traditional village, Hani minority settles itself, including 65 peasant households and 429 villagers (Kunming
Local Architectural Design Institute 2015). Ancestors of the Hani minority moved here over 1,300 years ago. The vast Ailao Mountain area domiciled by the 'most isolated minority group in the world' grants them the dense forest and clean water sources. Due to their tenacious and tough character as well as their respect for nature, Hani people have created a harmonious style of living and production on a large scale and a unique cultural landscape system characterised by four-element system (forest-water-village-terrace system) in this harsh mountainous region. The history, the belief system, the cultural tradition and the social cooperation mechanism of Hani people have endowed the unique Cultural Landscape of Honghe Hani Rice Terraces with special connotations with special meaning and fame. Consequently, the structure, the elements, the natural and cultural environment of the cultural landscape of Honghe Hani Rice Terraces have not been subject to radical change in its history of more than 1,000 years; on the contrary, they have been well preserved and still valued as a perfect model of a harmonious ecosystem and healthy lifestyle of human beings (State Administration of Cultural Heritage of People's Republic of China 2013).

\section{Landscape of the Rice Terraces}

There are rice terraces of $0.8 \mathrm{~km}^{2}$ within Azheke Village, accounting for $45 \%$ of the village area. The Hani Rice Terraces are located at a high altitude, with a slope inclination ranging between 10 and 25 degrees, which form the marvellous texture along the slope, radiating and stretching around the mountain (Figure 2). The streams of Honghe and Tengtiao River are flowing through the village; besides, the mountain is covered by $598 \mathrm{mu}$ (about $39.87 \mathrm{ha}$ ) forest, which contains enormous water resources. Ditches and channels of $5 \mathrm{~km}$ long in total are dug in the mountain. The rice terraces change with the landform and the water falling from the mountain is flowing at all seasons. Thanks to the sufficient water all the year round, the rice grows vigorously and good harvest can be guaranteed, which thus form an ecological cycle pattern of 'the forest fostering the field and the field cultivating the forest', as the fairyland landscapes highlighting rural scenes, village, forest, rounding clouds and mist (Shanghai Tongji Urban Planning \& Design Institute 2013).

At present, a great number of tourists have been swarming into Hani Rice Terraces for sightseeing and photography in a simple manner, which is characterised by high quantity of tourists and short time of stay. This simple way of development by relying on the increase of tourists not only features limited income but greatly damages the 

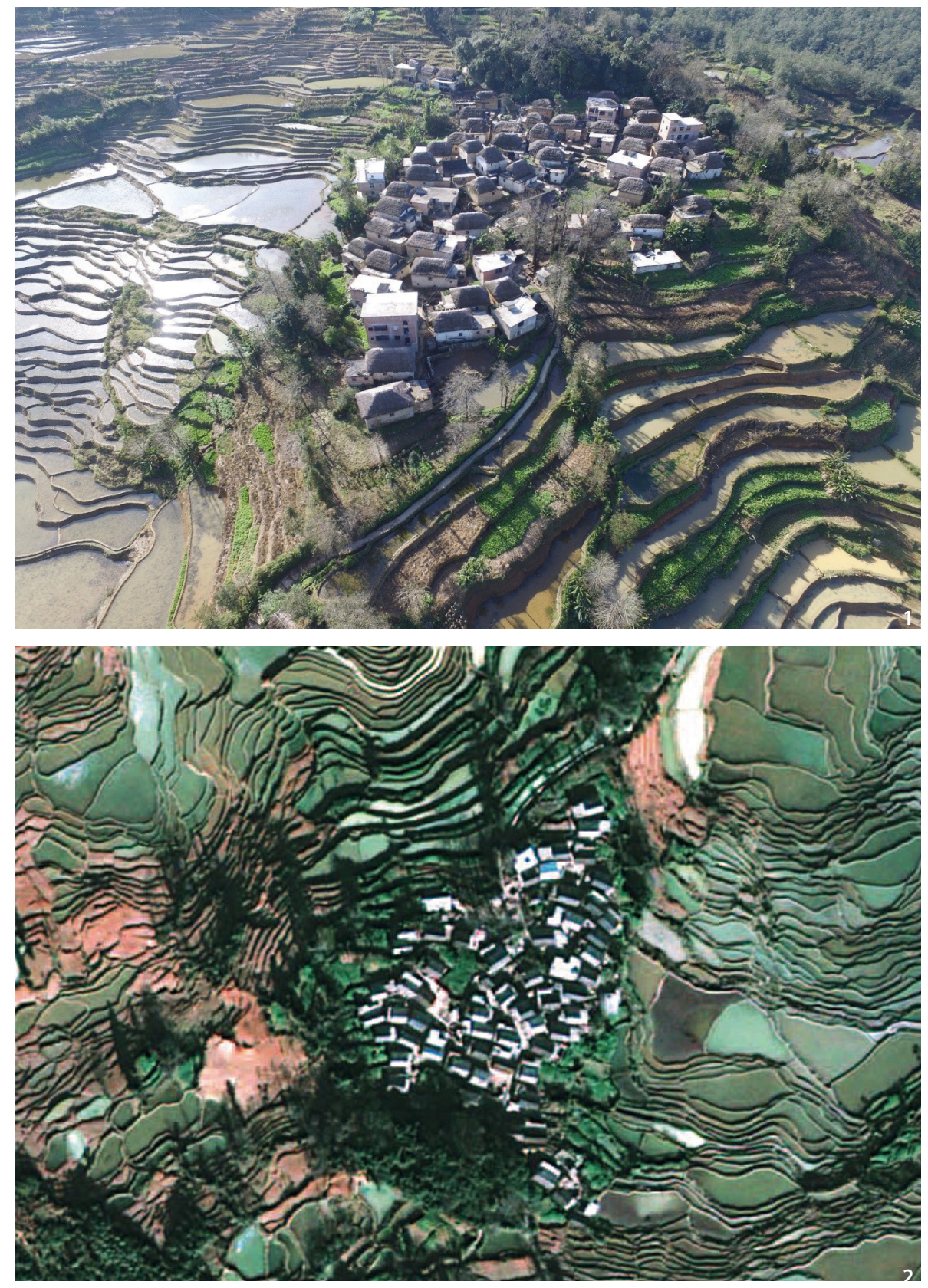

Figure 1 Overall Perspective of Hani Rice Terrace at Azheke Village (Source: Guangqiang Zheng).

Figure 2 Landscape of the terraced fields (Source: World Heritage Convention Cultural Heritage Nominated by People's Republic of China, Cultural Landscape of Honghe Hani Rice Terraces).

landscape environment. Hani Rice Terraces have been all relying on the natural eco-cycle system with the spring water running through channels from top to bottom for the purpose of drinking, living and public restrooms respectively, and then flowing into the terraces as irrigation water. As there is no manual sewage treatment system, nor solid waste classification and recycling facilities, the great increase in the number of tourists swarming into the village in a short period of time has greatly surpassed the environmental capacity, thus damaging the natural recycling and purification system. As found in the survey, part of the channels have been jammed with waste. As a result, the flow of water in the channels has been blocked, compromising the safety and health of water resources due to pollution (Figure 3a, Figure 3b). As a result, the normal supply of drinking water to the residents at the downhill cannot be guaranteed and part of channels have been even dried up. The water demanded by part of rice terraces cannot be fulfilled and their tillage may be threatened.

\section{Traditional Village Landscape}

Azheke, the traditional village inhabited by the Hani minority, has been preserved up to now in a complete manner. The dwellings are mostly characterised by the mushroom house design. At present, there are 67 mushroom houses in the village distributed in a centralised 

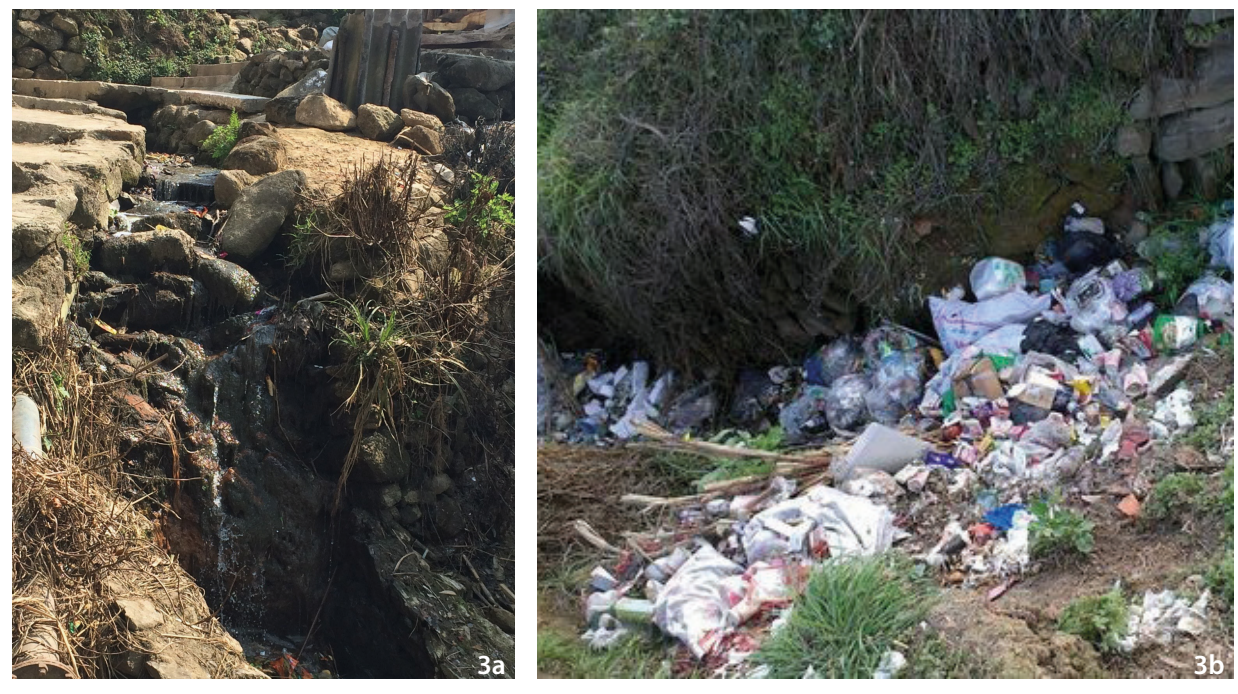

Figure $3 a$ and $3 \mathbf{b}$ The Polluted Channel (Source: Ming Qiu).

manner, among which, the earliest one can be dated back to 1855 . The mushroom house, constructed by the soil matrix walls, the bamboo and wooden frame as well as the thatch roof, looks like a square concerning its plan. The roof has four slopes with short ridge and steep slope, like a mushroom (Figure 4a, Figure 4b). There is a fireplace in the middle of the house where the fire is never extinguished. People from Hani minority have been following their ancestors' wisdom in terms of location selection, construction process and rules in constructing a mushroom house, which can be verified by the epic songs and the rites. The whole process has been written as a complete scientific and vivid manual; so it is described in the epic of Hani Minority-Hani Apei Congpopo: 'The high mountains in Reluo are surrounded by red flowers and green trees with mushrooms growing everywhere. The small mushrooms are never afraid of wind and rain and their beauty is unforgettable.' The well and the water-powered grinding room function as important public communication places. At present, there are five well-preserved wells in the village; two water-powered grinding rooms are located beside the ficus altissima, the core area of the village and beside the grinding field downward the village respectively. The villagers use the water-powered grinder and the air-blower as well as other tools for food processing. The ancient trees, the ancient wells, the bamboo grove, the stockade doors, the mushroom houses, Zhai Shen Lin (the Second Month Festival) and the water-powered grinding rooms all constitute the cultural elements of Azheke Village and the unique village landscapes.

However, many mushroom houses at Azheke Village have been left dilapidated at present with some even without thatch roof, which has affected the village's overall landscape. Part of houses are dilapidated, dark and humid inside with very bad dwelling conditions. Some house owners established or reconstructed their mushroom houses after earning money outside, or directly abandoned the mushroom houses (Figure 5a, Figure 5b). Listing of the houses is evidenced through a plate hanging outside the dwelling, indicating its status. Listing has established that 52 out of 67 dwellings are receiving rigorous protection; meaning that they cannot not be dismantled; one dwelling with minor transformations has been set for renovation to recover its traditional features; and 14 dwellings which have been seriously transformed will be reconstructed, implying the demolition of any added structure above three floors, the recovery of the original thatched roofs and the incorporation of traditional features in their walls. (Yuanyang County 2015). The public landscape in the village is very rough and the environment is dirty in disorder. There is only one stone road full of bumps and hollows for entering the village, which is greatly inconvenient. The house interval is uneven with relatively narrow public space. Only a space of $10 \mathrm{~m}^{2}$ is reserved for the villagers' activities. Although the local government has listed the mushroom houses in Azheke Village for protection, definitely prohibiting the villagers from dismantling and construction, the villagers with high income felt impatient to construct new houses at the village entrance. Thus there are enormous illegally-constructed houses at the village entrance, which has thus affected the village's entire landscape (Figure 6a, Figure 6b). Considering the request of maintaining the authenticity of traditional dwellings and complete protection on the one hand, the urgent demand of local villagers to improve their dwelling conditions on the other hand, the conflict between the two emerges once and again. 

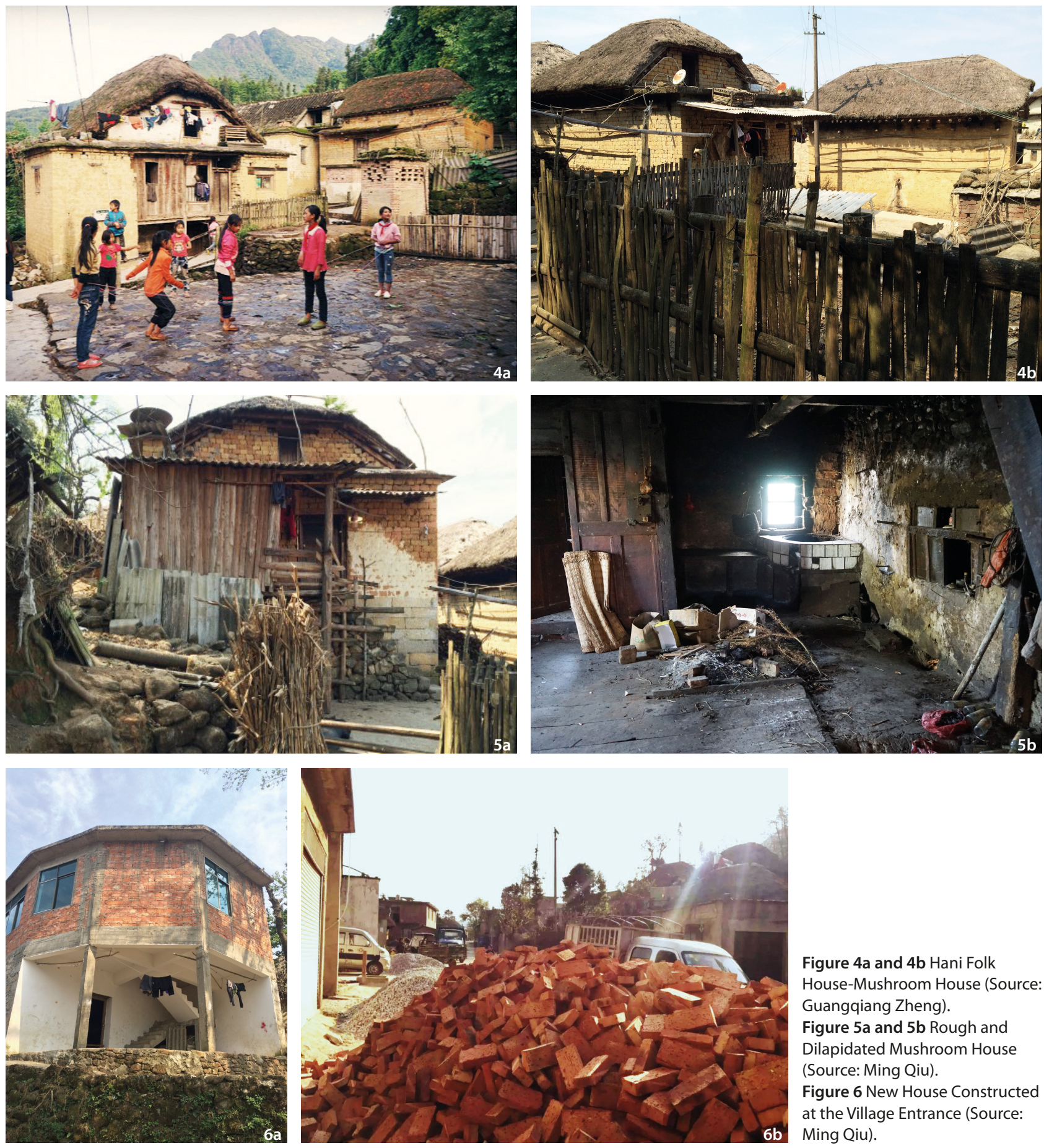

Figure $4 \mathrm{a}$ and $4 \mathrm{~b}$ Hani Folk

House-Mushroom House (Source: Guangqiang Zheng).

Figure $5 \mathrm{a}$ and $5 \mathrm{~b}$ Rough and Dilapidated Mushroom House (Source: Ming Qiu).

Figure 6 New House Constructed at the Village Entrance (Source: Ming Qiu).

\section{Local Culture}

The folk culture at Azheke is mysterious and colourful, such as the rice planting culture of Hani Rice Terraces, which highlights complete fertiliser system, fermentation system and terrace transportation system. The production and living landscape including windmill, sifter, water-powered trip-hammer and stone mill, etc. still continue up to now. The village has its rules and conventions as well as the folk customs, such as the fireplace culture and the water diversion system, the ethnic culture and the sacrifice activities, such as the sacrifice of the village god, the Angmatu Festival that worships the dragon and prays for rainfall, the Kuzhazha Festival when people kill ox for sacrifice, wrestle and play the drum solos (Yuanyang County 2015), the October Festival when people pound glutinous rice paste and hold the campfire party, the traditional handcrafts represented by local building craft, clothes manufacturing and embroidery (Figure $7 \mathrm{a}$, Figure $7 \mathrm{~b}$ ). Even now, the villagers are still wearing 

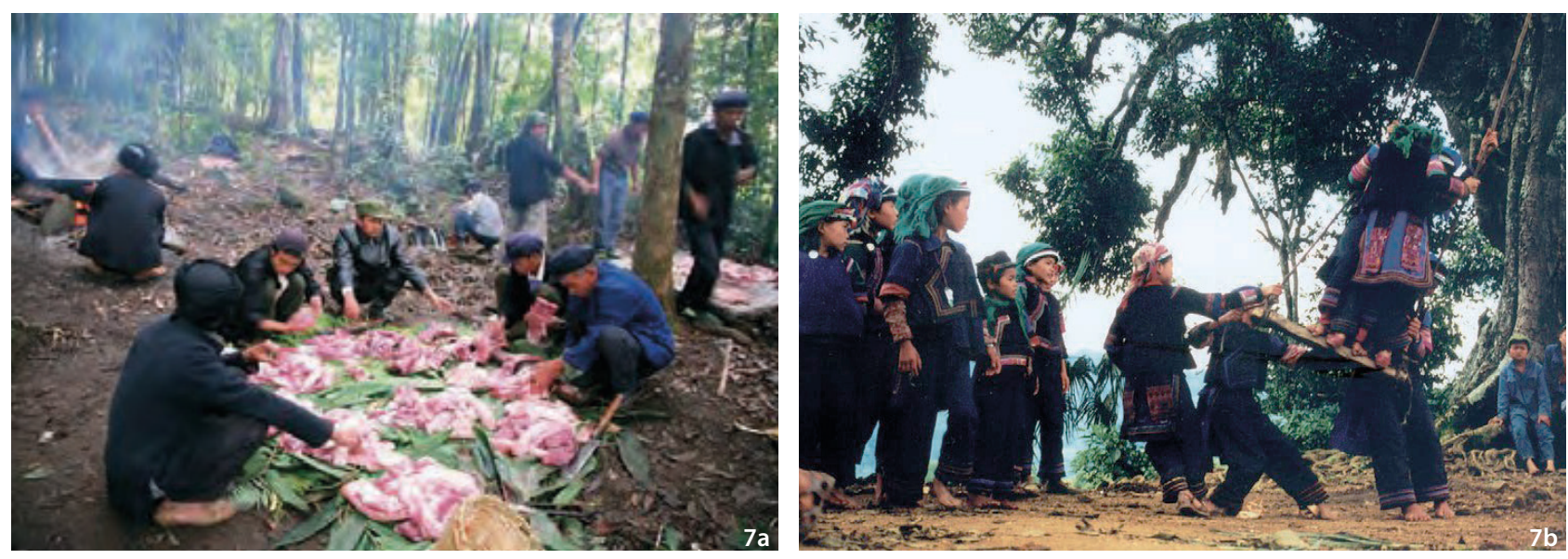

Figure 7a Zhai Shen Lin (the Second Month Festival) (Source: World Heritage Convention Cultural Heritage Nominated by People's Republic of China, Cultural Landscape of Honghe Hani Rice Terraces).

Figure 7b Postcard Reflecting Hani Culture (Play on the Swing) (Source: World Heritage Convention Cultural Heritage Nominated by People's Republic of China, Cultural Landscape of Honghe Hani Rice Terraces).

traditional clothes in their daily work and life. The Hani minority has a tradition of oral transmission of knowledge, meaning that these ancient, splendid and mysterious folk cultures containing the essence of the rural landscape of Azheke Village are handed down from generation to generation without written records.

With the population loss and change of the production method, the rice planting culture that Hani minority has undertaken for hundreds of years is confronted with great challenges. Many traditional folk-customs, local songs and dances, handcraft art and festival activities based on Hani people's daily life have been changed and even disappeared gradually. Hani people, no matter male or female, old or young, would wear what they liked most to swing in the past, but now, the swing in the village has been abandoned. Hani people used to treat guests beside the fireplace with hookah and stuffy pot wine as well as the specific Haini ballad that was well-rooted just like the bamboo on Ailao Mountain, but now, less fragrance of wine and the songs can be found, and even the folk customs have changed. The children may ask for money with the tourists at the village entrance and the local women engaged in hand work also do so when someone takes a photo.

The dwellings and the local culture at Azheke Village have been subject to external impact to different extents. The status quo of their value is not guaranteed while the authenticity, integrity and sustainability of the rural landscapes are confronted with great challenges. The village will face an increase in the number of tourists in its future development. Under these actual conditions, how to protect, undertake and develop the core value of Azheke
Village, as 'the traditional Hani minority village preserved most completely within the scope of World Heritage site: Hani Rice Terrace'?

\section{Planning Measures}

\section{Establishment of the Sense of Pride and Belong- ing among the Community Villagers to Hani Rice Terrace}

The field investigation and interviews were adopted to survey the villagers' view about the heritage and tourism of Hani Rice Terraces. The local villagers believed that 'the terrace tillage technology is handed down generation by generation. They did not know what the World Heritage and significance of the value of Hani Rice Terraces were. In respect of the tourism development, it was welcomed by the local people because 'they can earn some money by selling something to the tourists'; in the meanwhile, there were also people reflecting that 'it would be a little noisy to have more people outside. They felt rather strange but yearning for the external world. As the local villagers have been always isolated from the external world, they neither knew what the heritage tourism would bring about to them nor which impact it would exert on their life. They most expected to increase their income, get rid of poverty and lead a better life as soon as possible.

The Heritage Manual of the Hani Rice Terraces highlights how 'the World Heritage shall be a unique place for dwelling' (UNESCO 2015). It tells the local villagers that this land where their ancestors have been living generation by generation is very precious. The tillage of Hani Rice Terraces is full of wisdom. Hani Rice Terraces are 
'great earth sculptures' and Hani people are the 'sculptors of earth'. It tells them the reasons for the development of tourism because many people are feeling very interested in the mysterious Hani Rice Terraces and their culture. We will assist them in participating in the tourism activities so that they will secure benefits from tourism activities. The landscape and culture of Hani Rice Terraces shall be handed down from their hand because they are the indeed masters of the World Heritage site.

At meanwhile, the local government was suggested to train and guide villagers. As Azheke villagers were not well educated, especially the old and the women who were rarely educated, they usually communicated in native language and can only speak a little mandarin, it would be very difficult for them to be directly engaged in the tourism services. Therefore, the education and training would be the foundation to realise the interests of these community residents. In addition to the language training, there would be training in terms of tourism service skills (tour guide service, dining service, homestay service and maintenance of infrastructure facilities, etc.), characteristic handicraft making, traditional handcraft, folk festivals and customs passed on to the local young people.

\section{Creation of the Mode and Approach for the Com- munity Villagers to Participate in the Sustainable Tourism}

Endeavours shall be made in order to provide more valuable job opportunities to the local people, enabling them to benefit from heritage tourism by offering a variety of possible occupations to perform, as well as listing sustainable tourism activities with which the residents can engage with our guidance and assistance. The value of Hani Rice Terraces not only relies on their visual beauty and appreciation but the wisdom that integrates mankind and nature. It enlightens modern people to respect nature. Such education experience, exactly ignored and lacked by the current tourism approach, is also our planning emphasis. As a matter of fact, the education and the emotional experience just originate from the daily production of Hani people. The local villagers shall be the best subjects who can provide some authentic tourism activities on the heritage site filled with enthusiasm and education experience rather than the theme-based park or performance stage isolated from the authenticity of rural landscape. It is the exact important impetus of heritage tourism to seek the sense of authenticity (Harrison 2004).

- Instruct and Demonstrate the Terrace Tillage Considering the representation of value of the global agricultural heritages and value of the world cultural landscape heritages as the core, efforts will be made to explain the value and characteristic of Hani Rice Terraces in an overall and systematic manner to increase the tourists' recognition and understanding of the value of rice planting culture in the course of interactive and experiencing projects, for example, set the 'four-element system walking route': Zhai Shen Lin (the Second Month Festival)-main water system of the village-main stem of the village terraced fields at the corner, where the local villagers may introduce the tillage flow and characteristics of Hani Rice Terraces; set the terraced fields of $10 m u$ (about $0.67 \mathrm{ha}$ ) for tillage experience so that the tourists and the villagers may seed, experience the tillage and harvest of Hani Rice Terraces in person together. Besides, the red rice experience pavilion shall be built to show, taste and sell red rice from Hani Rice Terraces (Zhang 2017). On the one hand, the tourists can profoundly feel the miracle and precious value of Hani Rice Terraces; on the other hand, Hani people's sustainable utilisation of land and their life with land can be represented and understood in an authentic manner.

- Develop Hani Culture Tourism Products

Efforts can be made to design the tourism commodities with Hani products and Hani ethnic culture as the core, guide villagers to spread Hani food culture, develop the terrace series food: terrace chicken, terrace duck, terrace egg, terrace fish, and terrace loach, guide the villagers to be engaged in the making of traditional handcrafts, such as Hani woodcarving, Hani traditional clothes, bamboo weaving, thatch weaving, dying, Hani fairy stories and movies.

- Encourage the villagers to perform as tour guides

As an important tool of heritage tourism planning and management, the interpretation system can ensure long-term protection of natural and cultural resources by fostering positive attitudes towards preservation and appreciation of the environment with a view to enhancing the quality of visit experience and create sustainable connections between tourism and built heritage (Moscardo 1996). The local residents shall play an important role in receiving tourists and interpreting the value of heritage. As indicated by experience, native people shall be encouraged to work as the tour guide to further enhance tourists' emotional experience by telling stories based on their own personal place experience especially the aboriginal cultural experience through their verbal interpretation (Zeppel and Muloin 2008). It is hereby suggested that the education and training will encourage community residents to convey their feelings, values, 
stories, culture (including related activities such as daily folk customs and family life), and knowledge (including their wisdom about the local special plants), around the core value of Hani Rice Terraces; aspects which are currently lacking in the tourism narration of heritage sites in China, and that cannot be provided by non-native tour guides (Yang and Chen 2009).

\section{Improving the Interest of Community Residents by the Development of Heritage Tourism}

At present, the villagers at Azheke Village are leading a very poor life with an annual income per capita of only 3,000 RMB. Therefore, the local residents would like to increase their income and improve their living conditions immediately, which is also one of the missions of the sustainable development of heritage tourism. Only after the local villagers lead a prosperous life, would they feel comfortable staying. The primary product and source of income here is their red rice. In comparison with the modern high-carbon agriculture highlighting high investment and high output, the traditional agriculture at Hani Rice Terraces has not damaged the regeneration ability of the ecosystem but maintained the diversity of local species and biotope, and established a stable and superior rice variety. As Hani Rice Terraces have been always relying on the primitive manual tillage, the rice from such terraced fields features superior quality but less output and low income; therefore, fewer and fewer young people are engaged in the tillage of terraced field. They prefer to work and earn more outside. In this sense, the core problem is how to encourage local residents to continue tillage at the terraced fields, achieve direct benefit, attract more young people to return to the heritage site, and devote to the agricultural production, which shall be supported by the government policies with cooperation with commercial enterprises and introduction of social charity institutions. At present, the organisation for public welfare, 'Half City and Half Countryside' has taken the initiatives to assist the villagers in implementing the 'red rice plan' by packing, selling and promoting red rice for the sake of Hani people.

- Reconstruct and Renew the Value of Traditional Dwellings

The mushroom houses, as an important constituting part of the cultural landscape heritage of Hani Rice Terraces, represent the economy, technology, society and aesthetics of Hani people. Thus they have representative value, they have stories and memories to express on individual and collective life in the past. In this sense, these mushroom houses signify ethnic and local significance; nevertheless, many mushroom houses have been dilapidated due to lack of repair for many years and cannot fulfil the villagers' demand of improving their dwelling conditions. Indicated by research, throughout the European countryside, many traditional farm buildings have lost their original use and thus been currently subject to a gradual process of decay (Fuentes 2010). Thus the innovative re-utilisation of the mushroom houses in combination of the tourism function is an effective approach to balance, protect and improve the dwelling conditions.

In Spain, it can be estimated that more than 400 million of Euros were allocated by the EU LEADER and PRODER programs to preserve and maintain the countryside cultural heritage for the period 1991-2000. An important part of these funds were devoted to converting old vernacular constructions into rural tourism establishments (Fuentes 2010). In reference to this experience, the idle mushroom houses can be reconstructed for utilisation so as to grant them with new functions together with Hani culture, such as the red rice restaurant, the terrace fisherman's family, the hand knitting workshop, the woodcarving exhibition room, the rice wine experience room, the homestay, and the Hani museum, which enables tourists to feel the characteristics of Hani traditional dwellings and understand the authentic life of Hani people, and also improves the utilisation value of these mushrooms (Zhang 2017). In the meanwhile, repairing the mushroom houses is a priority. Experience indicates that the interior reconstruction would be more acceptable in comparison with the house's appearance; therefore, the reconstruction would respect the structural completion, individuality and form of the mushroom houses on the one hand; on the other hand, the reconstruction shall protect their original appearance, material and landscape characteristics, especially the thatch roof. In addition, the interior space shall be renewed and reconstructed to fulfil the villagers' demand of modern life and pass on Hani's life, culture and the interior spirit as well.

\section{- Revitalise Local Festivals}

The community members, who were not previously engaged in tourism would become more involved in the tourism activities by selling and promoting special products of their region in festivals. In this interaction process, community members shared their identity with other residents who eventually embraced it as their own (Hwang et al. 2012). The northern side of the village, where the original sacrifice room and the grinding field were located, will be planned to the site for traditional sports and cultural activities, such as Hani's swing playing and grinding; the southwest side of the village where the original 
Zhai Shen Lin (the Second Month Festival) was located is planned to be the area of Hani traditional festivals such as sacrifice activity, Kuzhazha Festival and Angmatu Festival. On normal days, the history of Hani minority can be described verbally by means of storytelling, which is often embodied in ritual.

\section{Conclusions and Discussion}

In the past 40 years, the UNESCO World Heritage Convention has preserved, protected and presented the OUV of our shared heritage. The UNESCO 'World Heritage and Sustainable Tourism Programme' represents a new approach based on dialogue and stakeholder cooperation, in the course of which the planning of tourism and heritage management has been integrated at a destination level, and the natural and cultural assets are valued and protected to develop tourism appropriately (UNESCO 2015). As far as the sustainable tourism development of the rural landscape heritage sites is concerned, the problems will be more comprehensive and complex while the human are interacting with nature in a continuous manner. The large number of theoretical approaches and operational tools to deal with the study and safeguarding the heritage values of rural landscapes, reflects the diversity and complexity of disciplines, socio-cultural contexts and administrative organisations of each geographical area (ISCCL 2017). The community residents shall be considered as an integral part of the rural landscapes; therefore, the sustainable tourism development of the rural landscape heritage cannot only protect the natural and biodiversity, but protect the structure and the human history of land utilisation. Maintenance of the traditional way of living, on this basis, can provide education and understanding of exhibiting the durable use of system in harmony with nature. The key to realise the objectives is to fully respect the master status of local community residents at the heritage sites, create manners and approaches for the community residents to participate in the rural sustainable tourism, help the community residents to improve the living quality and vitality in the course of tourism development, enable the tourism industry to instruct the behaviours of community residents in an active and positive manner, and thus protect, represent and undertake the rural landscape heritage initiatively. It is an ideal status. As a matter of fact, many problems and challenges will still remain, continuous observation and discussions are also necessitated in future research.

With gradual access of external commercial factors to Azheke Village, for example, purchasing the villagers' mushroom houses to establish the homestay, the local community residents are marginalised due to their disadvantages in terms of capital, experience and education. If all the tourism products are provided by external enterprises, there would be no merit to the local residents for supporting the tourist experience. Numbers indicate that it would also result in economic leakage. Although the tourism brings significant tourists to the region, it gives little indication of the actual value of tourism to the communities in terms of employment and turnover, and the tourism income finally flows out of the community (Gilbert 2006). In addition, the traditional way of survival for the community residents would be rigorously restricted and they would become the victims of tourism development (Jin 2009); therefore, more attentions will be paid to Azheke Village by creating job opportunities to the local residents to establish its own industry.

The access of tourists will inevitably affect the architecture, the facilities and the way of land utilisation. Modern tourism facilities may easily ignore the sensitivity of the sacred qualities of land. What is worth mentioning that in rural communities fighting for recognition from the tourist retailers, the wholesale rushing to the market communities on the strength of heritage implies risks, which will turn such communities into 'museums of themselves' (Kirshenblatt-Gimblett 1996). If the historical exhibits such as museums, celebrations, architecture and streetscapes are only valued for their tourist potential, they may lose their role in the daily life of the community and their value as the consumer commodities may overwhelm their value as places of memory for community members (Gilbert 2006). In this sense, more attentions will be paid to Azheke Village in the future to balance the relationship between the tourist demands and the authenticity and integrity of the heritage site.

There is no doubt that the traditional culture of Hani minority is the intangible cultural heritage in demand of protection. UNESCO Declaration on Cultural Diversity in 2001 acknowledged the basic function of human right protection of indigenous people, including respect of traditional knowledge and its contribution, etc. For most indigenous communities, the culture and heritage are intimately associated with their lands (Gilbert 2010). As driven by the economic interests with impacts on the community traditions by the external culture and concepts resulting from the tourism industry, the traditional way of tillage, language, handcraft, music, dance and sacrifice activities, etc. are all confronted with crisis. Australia ICOMOS 2001 asserts that 'the indigenous cultural 
heritage significance of places can only be determined by the indigenous communities themselves' (Logan 2012). What should be done if, pursuing the benefits of modern urban life, the local community chooses to abandon their tradition and agriculture and devotes itself to the tourism industry? 'In order to enable more other people to be benefited from the World Heritage, whether will the local people make some contribution and be forced to maintain their traditional way of living.' (Aplin 2007)

Honghe Hani Rice Terraces have just been listed as the World Heritage for three years and the tourism development has just commenced. Based on some thoughts of sustainable tourism development and planning of local place in the early stages, this paper finds some problems, and proposes some counter-measures and suggestions. In the future, scholars need to continue to study rural landscape transformations and the dynamic tourism development of Azheke Village, collect, record and analyse the opinions of local communities regularly in hopes of making some quantified research and exploration in terms of environment, tourist behaviour and community development ${ }^{1}$.

\section{Notes}

1. The following information has provided basic materials to the research:

http://whc.unesco.org/en/convention/

http://whc.unesco.org/en/tourism/

World Heritage Convention Cultural Heritage Nominated by People's Republic of China, Cultural Landscape of Honghe Hani Rice Terraces

\section{Acknowledgements}

This study is financially supported by a Youth Science Fund Project of the National Natural Science Foundation of China, Coupling Mechanism of Local Culture Heritage and Modern Rural Tourism Development-Taking Wannan Villages as the Study Case (51408431).

\section{References}

Añón Feliú, Carmen. 2003. Culture and Nature: International Legislative Texts Referring to the Safeguard of Natural and Cultural Heritage. Perugia: Olschki.

Aplin, Graeme. 2007. "World Heritage Cultural Landscapes." International Journal of Heritage Studies 13 (3): 427-446.

Bramwell, Bill, and Angela Sharman. 1999.“Collaboration in Local Tourism Policy Making." Annals of Tourism Research 26 (2): 392-415.

Chhabra, Deepak, Healy Robert, and Sills Erin. 2003. "Staged Authenticity and Heritage Tourism." Annals of Tourism Research 30 (3): 702-719.

Cooper, Charlie, and Nigel Morpeth. 1998. “The Impact of Tourism on Residential Experience in Central-eastern Europe: The Development of a New Legitimation Crisis in the Czech Republic.” Urban Studies 35 (12): 2253-2275.

Dogan, Gursoy, Christina G. Chi, and Pam Dyer. 2010. "Locals' Attitudes toward Mass and Alternative Tourism: The Case of Sunshine Coast, Australia." Journal of Travel Research 49 (3): 381-394.

Donohoe, Holly M. 2012. "Sustainable Heritage Tourism Marketing and Canada's Rideau Canal World Heritage Site." Journal of Sustainable Tourism 20 (1): 121-142.

Drost, A. 1996. "Developing Sustainable Tourism for World Heritage Sites." Annals of Tourism Research 23 (2): 479-492.

Fuentes, José María. 2010. “Methodological Bases for Documenting and Reusing Vernacular Farm Architecture." Journal of Cultural Heritage 11 (2): 119-129.

Gilbert, Jeremie. 2010. "Custodians of the Land: Indigenous Peoples, Human Rights and Cultural Integrity." In Cultural Diversity, Heritage and Human Rights: Intersections in Theory and Practice, edited by Michele Langfield, William Logan, and Mairead Nic Craith, 31-44. London: Routledge.

Gilbert, Susan. 2006. “Finding a Balance: Heritage and Tourism in Australian Rural Communities." Rural Society 16 (2): 186-198.

Gullino, Paola, and Federica Larcher. 2013. "Integrity in UNESCO World Heritage Sites: A Comparative Study for Rural Landscapes.” Journal of Cultural Heritage 14 (5): 389-395

Han, Feng. 2012. "Cultural Landscape: Marching on the Way of Exploration." Chinese Landscape Architecture 28 (5): 5-9.

Harrison, David. 2004. "Contested Narratives in the Domain of World Heritage." Current Issues in Tourism 7 (4-5): 281-290.

Hopkins, J. 1998. "Commodifying the Countryside: Marketing Myths of Rurality." In Tourism and Recreation in Rural Areas, edited by Richard W. Butler, C. Micheal Hall and John Jenkins,139-156. New York: John Willey and Sons.

Hwang, Doohyun, William P. Stewart, and Dong-wan Ko. 2012. “Community Behavior and Sustainable Rural 
Tourism Development." Journal of Travel Research 51 (3): 328-341.

ICOMOS/IFLA International Scientific Committee on Cultural Landscape (ISCCL). 2017. World Rural Landscapes. Accessed Nov 10 2017. http://www.worldrurallandscapes.org

Jin, Huihua, 2009. “The Impact of Development Projects on Aboriginal Environmental Rights: Focusing on the World Bank Indigenous Peoples Policy." [Lun fazhan xiangmu dui tuzhu jumin huanjingquan de yingxiang: yi shijie yinhang tuzhumin zhengce weili] Political Science and Law 2009 (7): 137-142.

Kang, Soo K., Choong-Ki, Lee, Yooshik Yoon, and Patrick T. Long. 2008. "Resident Perception of the Impact of Limited-Stakes Community-Based Casino Gaming in Mature Gaming Communities.” Tourism Management 29 (4): 681-694.

Kirshenblatt-Gimblett, B. 1996. "Tourism and Heritage." In Traditions and Tourism: The Good, the Bad and the Ugly Proceedings of the Sixth National Folk Life Conference, edited by G. Davey, and S. Faine Susan, 25-30. Melbourne: The National Centre for Australian Studies Monash University and the Victorian Folk Life Association.

Kunming Local Architectural Design Institute, Faculty of Architecture and City Planning of Kunming University of Science and Technology. 2015. Protection and Development Planning of Yuanyang Azheke Traditional Village (2014-2030).

Knowd, Ian. 2006. "Tourism as a Mechanism for Farm Survival." Journal of Sustainable Tourism 14 (1): 24-42.

Lee, Sean, Ian Phau, Michael Hughes, Fengli Yu, and Vanessa Quintal. 2016. "Heritage Tourism in Singapore Chinatown: A Perceived Value Approach to Authenticity and Satisfaction." Journal of Travel \& Tourism Marketing 33(7): 981-998.

Lennon, Jane, and Feng Han. 2012. "Rural Landscapes." Chinese Landscape Architecture 2012 (5):19-21.

Liu, Binyi, and Chen Wei. 2005."Pondering over the Planning and Development of Landscape in Towns and Villages at Present in China." [Guanyu zhongguo muqian xiangcun jingguan guihua yu jianshe de sikao.] Development of Small Cities \& Towns 2005 (9): $45-47$.

Logan, William. 2012. "Cultural Diversity, Cultural Heritage and Human Rights: Towards Heritage Management as Human Rights-based Cultural Practice." International Journal of Heritage Studies 18 (3): 231-244.

Loulanski, Tolina, and Vesselin Loulanski. 2011. "The
Sustainable Integration of Cultural Heritage and Tourism: A Meta-study." Journal of Sustainable Tourism 19 (7): 837-862.

MacCannell, Dean. 1973. "Staged Authenticity: Arrangements of Social Space in Tourist Settings." American Journal of Sociology 79 (3): 589-603.

Moscardo, Gianna. 1996. "Mindful Visitors: Heritage and Tourism." Annals of Tourism Research 23 (2): 376-397.

Noha, Nasser. 2003. "Planning for Urban Heritage Places: Reconciling Conservation, Tourism, and Sustainable Development." Journal of Planning Literature 17 (4): 467-479.

Peng, Yigang. 1992. Chuantong cunzhen juluo jingguan fenxi [Landscape Analysis on the Traditional Settlement of Villages and Towns]. Beijing: China Architecture \& Building Press.

Plieninger, Tobias, Franz Höchtl, and Theo Spek. 2006. "Traditional Land-use and Nature Conservation in European Rural Landscapes." Environmental Science and Policy 9: 317-321.

Poria, Yaniv, Richard Butler, and David Airey. 2006.“Tourist Perceptions of Heritage Exhibits: A Comparative Study from Israel." Journal of Heritage Tourism 1 (1): 51-72.

Poria, Yaniv, Arie Reichel, and Avital Biran. 2006. "Heritage Site Management: Motivations and Expectations." Annals of Tourism Research 33 (1): 162-178.

Poria, Yaniv, Richard Butler, and David Airey. 2003. "The Core of Heritage Tourism." Annals of Tourism Research 30 (1): 238-254.

Richard, R. Perdue, Patrick T. Long, and Yong Soon Kang. 1995. "Resident Support for Gambling as a Tourism Development Strategy." Journal of Travel Research 34 (2): 3-11.

Ryan, Jason, and Sari Silvanto. 2010. "World Heritage Sites: The Purposes and Politics of Destination Branding." Journal of Travel \& Tourism Marketing 27 (5): 533-545.

Shanghai Tongji Urban Planning \& Design Institute. 2013. "General Planning of Yuanyang Tourism Development (2013-2030).”

Shen, Suyan, Anke Schüttemeyer, and Boris Braun. 2009. "Visitors' Intention to Visit World Cultural Heritage Sites: An Empirical Study of Suzhou, China." Journal of Travel \& Tourism Marketing 26 (7): 722-734.

State Administration of Cultural Heritage of People's Republic of China. 2013. World Heritage Convention Cultural Heritage Nominated by People's Republic of China: Cultural Landscape of Honghe Hani Rice 
Terraces. http://whc.unesco.org/uploads/nominations/1111.pdf

Taylor, Ken, and Jane Lennon. 2011. "Cultural Landscapes: A Bridge between Culture and Nature?” International Journal of Heritage Studies 17 (6): 537-554.

Tazim, B. Jamal, and Donald Getz. 1995.“Collaboration Theory and Community Tourism Planning." Annals of Tourism Research 22 (1): 186-204.

Timothy, Dallen J. 2003. Heritage Tourism. London: Pearson Education/Prentice Hall.

Tong, Mingkang. 2012. "To Protect the World Heritage for Sustainable Development." [Baohu shijie yichan mouqiu kechixu fazhan] China Cultural Heritage (5): $12-17$.

UNESCO. 1962. Recommendation Concerning the Safeguarding of the Beauty and Character of Landscapes and Sites. Paris: UNESCO. http://portal.unesco. org/en/ev.php-URL_ID=13067\&URL_DO=DO_ TOPIC\&URL_SECTION=201.html

UNESCO. 2010. Policy Orientations: Defining The Relationship between World Heritage and Tourism. Paris: UNESCO. http://whc.unesco.org/en/decisions/4240/

UNESCO. 2013. UNESCO World Heritage and Sustainable Tourism Programme. http://whc.unesco.org/uploads/activities/documents/activity-669-7.pdf

UNESCO. 2015. Operational Guidelines for the Implementation of the World Heritage Convention. Paris: UNESCO. http://whc.unesco.org/en/guidelines/

UNESCO. 2015. UNESCO World Heritage Sustainable Tourism Toolkit. http://whc.unesco.org/sustainabletourismtoolkit/

United Nations. 1992. Annex of the Rio Declaration on Environment and Development.

Wang, Yinglin. 2014. Multiple Values Identification Based Research on the Community Planning in the National Park of China. Beijing: Tsinghua University.

Weiler, Betty, and Aise Kyoungjin Kim.2011. “Tour Guides as Agents for Sustainability: Rhetoric, Reality and Implications for Research." Tourism Recreation Research 36 (2): 113-125.

Yang, Hongying, and Hui Chen. 2009."Analysis of Tour Guide Interpretation in China.", In Tourism in China: Destination, Cultures and Communities, edited by Chris Ryan and Huimin Gu, 225-236. New York: Routledge Taylor \& Francis Group.

Yuanyang County. 2015. Archives of Traditional Chinese Villages-Azheke Village, Xinjie Town, Yuanyang County, Honghe Prefecture, Yunnan Province.

Zeppel, Heather, and Sue Muloin. 2008. "Aboriginal
Interpretation in Australian Wildlife Tourism." Journal of Ecotourism 7 (2-3): 116-136.

Zhang, Lin. 2017. “Tourism Rural Landscape Features and Landscape Planning: A Case Study of Azheke Village of Yuanyang County in Yunnan Province." Landscape Architecture (5): 87-93. 